\title{
The Prevalence and Risk Factors of Asthma, Allergic Rhinitis, and Eczema in Primary School Children, Zanjan, Iran
}

\author{
Akefeh Ahmadiafshar 1,2,3*iD, Saeid Nourollahi ${ }^{3}$ (D), Arezoo Arminpour ${ }^{3}$ (D), Soghrat Faghihzadeh Ad, $^{2}$
}

1. Social Determinants of Health Research Center. Zanjan University of Medical Sciences, Zanjan, Iran

2. Metabolic Diseases Research Center, Zanjan University of Medical Sciences, Zanjan, Iran

3. Dept. of Pediatrics, Mousavi Hospital, School of Medicine, Zanjan University of Medical Sciences, Zanjan, Iran

4. Dept. of Biostatistics, School of Medicine, Zanjan University of Medical Sciences, Zanjan, Iran

\begin{tabular}{|c|}
\hline Article Info \\
\hline doil $10.30699 / j a m b s .28 .130 .230$ \\
\hline $\begin{array}{l}\text { Received: 2020/05/07; } \\
\text { Accepted: 2020/09/16; } \\
\text { Published Online: } 21 \text { Sep 2020; }\end{array}$ \\
\hline $\begin{array}{l}\text { Use your device to scan and read the } \\
\text { article online }\end{array}$ \\
\hline 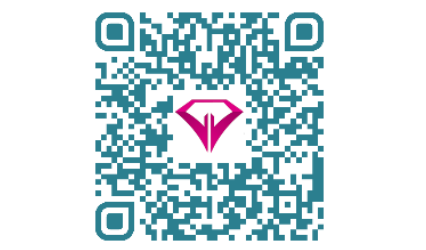 \\
\hline
\end{tabular}

Corresponding Information: Akefeh Ahmadiafshar,

Social Determinants of Health Research Center and Metabolic Diseases Research Center, Zanjan University of Medical Sciences, Zanjan, Iran

E-Mail: akefeh45@zums.ac.ir

\begin{abstract}
Background \& Objective: Allergies are manifested with a variety of signs and symptoms. In this study, the frequencies of asthma symptoms, allergic rhinitis, eczema, and related factors among 6- to 7-year-old schoolchildren were investigated.
\end{abstract}

Materials \& Methods: This cross-sectional study was carried out among schoolchildren of 35 elementary schools of Zanjan by using the International Study of Asthma and Allergies in Childhood (ISAAC) questionnaire consisting of the following: asthma symptoms, allergic rhinitis, atopic dermatitis, sex, weight, height, feeding, paracetamol and antibiotic use, maternal education, physical activity, exposure to pets or farm animals, heavy traffic exposure, and parental tobacco use. Data were gathered and analyzed by SPSS software.

Results: In this study, 800 children ( 383 girls and 417 boys) were recruited. The prevalence of wheezing was $28 \%$ (95\% Confidence Interval; 27,36), rhinitis $20 \%$ (95\% CI; 19, 27), and dermatitis $16.8 \%$ (95\% CI;13.1, 17.5). However, the rates of physician-diagnosed asthma, allergic rhinitis, and eczema were $1 \%, 8.9 \%$, and $4.1 \%$, respectively. The prevalence rates of asthma symptoms and atopic dermatitis were significantly higher in girls than in boys $(P=0.01$ and $P<0.001$, respectively). The weight of children with asthma was significantly higher than children without asthma $(P=0.01)$.

Conclusion: The frequencies of wheezing, rhinitis, and dermatitis among 6- to 7year-old children were high. Thus, symptoms and history should be considered for the accurate diagnosis and management of children.

Keywords: Diabetic retinopathy, RBP4, RBP4 delivery kinetic, Vitamin A

\begin{tabular}{|c|c|}
\hline (c) (1) (9) & $\begin{array}{l}\text { Copyright } \odot 2020 \text {, This is an original open-access article distributed under the terms of the Creative Commons Attribution-noncommercial } 4.0 \text { International License which permits } \\
\text { copy and redistribution of the material just in noncommercial usages with proper citation. }\end{array}$ \\
\hline
\end{tabular}

\section{Introduction}

Asthma is the most common inflammatory disorder in children. The inflammatory process in airways leads to obstructions that manifest as recurrent episodes of wheezing, breathlessness, chest tightness, and coughing. Airflow obstruction is also widespread and variable and shows mild to severe symptoms (1). Allergic phenomena have a wide range of symptoms and signs. The allergic march is appearances of atopic disease with eczema and progression to asthma, and then to allergic rhinoconjunctivitis (2).

Allergic rhinitis or rhinoconjunctivitis is a challenging allergic problem. It clinically diagnosed based on symptoms of nasal congestion, sneezing, rhinorrhea, and nasal or ocular pruritus, or it could be presented with eye tearing along with nasal symptoms (3).
Atopic dermatitis is a chronic inflammatory itchy skin rash, which often occurs in early infancy (4). It is a major risk factor for the development of asthma. Also, the risk of developing asthma among children with atopic dermatitis has been shown to be two times higher than in children without atopic dermatitis $(5,6)$. Allergic rhinitis is also a common disorder in patients with asthma (7). The recurrent and chronic nature of these disorders imposes a heavy burden on families and society because of significant health care costs and reduced daily activity and school function. Therefore, it could impair the quality of life of affected individuals $(8,9)$.

The prevalence rates of asthma and wheezing among 6- to 7-year-old children in Iran have been reported as $2.7 \%(95 \%$ confidence interval $(\mathrm{CI}) ; 1.9,3.6)$ and $7.6 \%$ (95\% CI; 5.6, 9.8), respectively (10). The prevalence of 
allergic rhinitis was also reported as being about $11-$ $40 \%$ in different parts of Iran (11-14). Some epidemiologic studies have shown that the prevalence of atopic dermatitis is $13.4-17 \%$ among children in different parts of the world $(4,6,13)$. Previous studies in Zanjan (among middle school students) have shown that the prevalence rates of asthma symptoms, allergic rhinitis, and atopic dermatitis were $13-15 \%, 14 \%$, and $12 \%$, respectively $(15,16)$. However, findings among younger children are limited. The aim of this study was to investigate the allergic symptoms among 6- to 7year-old school children in Zanjan.

\section{Materials and Methods}

This cross-sectional study was conducted from November 2016 to May 2017, and 1,000 children (6to 7-year-old) from 35 primary schools in Zanjan city were randomly selected by multivariate cluster sampling and entered the study. After description of the study, the International Study of Asthma and Allergies in Childhood (ISAAC) core questionnaire on asthma, rhinitis, and eczema (17) were given to children. They were asked to fill them out at home with the help of their parents (after giving consent). In addition, information about demographic findings and environmental factors was assessed by the ISAAC environmental questionnaire, including sex, weight, height, eating diet, two or more siblings, paracetamol use, antibiotic consumption, maternal education, exercise and television watching program, exposure to pets or farm animals, heavy traffic exposure, and parental tobacco use. Data were gathered and analyzed by SPSS 16 (SPSS Inc., Chicago, Ill., USA).

\section{Results}

Questionnaires were filled out and returned by 800 (out of 1000) 6- to 7-year-old children (383 girls and 417 boys). The prevalence of wheezing was $28.5 \%$ (95\% CI; 27, 36), and the prevalence of physiciandiagnosed asthma was $1 \%(95 \% \mathrm{CI} ; 0.6,1.2)$. Severe asthma symptoms, on the basis of night problem $>1$ /night problem, speech and activity limitation, were seen in $1.7 \%, 1.8 \%$, and $4.5 \%$ of children, respectively (Table 1).

Rhinitis symptoms were $20 \%$ (95\% CI [19, 27]), and the physician-diagnosed allergic rhinitis was $8.9 \%$ (95\% CI [8, 11]). Most of the children had mild symptoms of rhinitis (Table 2).

Itchy rash was also reported $16.8 \%$ (95\% CI [13.1, $17.5])$, and the prevalence of eczema was $4.1 \%(95 \%$ CI $[3,6])$ (Table 3).

The prevalence rates of asthma symptoms and atopic dermatitis were significantly higher in girls than in boys ( $P=0.01$ and $P<0.001$, respectively). There was no significant association of allergic rhinitis or atopic dermatitis with weight, height, and birth weight. However, the weight of children with wheezing was significantly higher than children without asthma. There was no association of a history of breastfeeding, having two or more siblings, number of hours spent watching television, or heavy traffic exposure with wheezing, rhinitis, and dermatitis. We found a significant association between fast food consumption and dermatitis $(P=0.04)$. Wheezing was significantly higher in children who had exposure to pets in the first year of life $(P=0.008)$.

However, there was also a significant correlation between asthma, wheezing, and dermatitis with exposure to pets during the last 12 months. There was a significant association between exposure to domestic animals in the first year of life and wheezing $(P=0.044)$ and rhinitis $(P=0.004)$ frequencies. The amount of physical activity per week was also significantly higher among children with wheezing $(P=0.000)$, rhinitis $(P=0.001)$, and dermatitis $(P=0.012)$. Parental tobacco smoking was significantly higher in children with rhinitis $(P=0.001)$ and dermatitis $(P=0.008)$. There was a significant association between paracetamol use in the first year of life and wheezing $(P=0.000)$ and rhinitis $(P=0.003)$. In addition, the frequency of antibiotic consumption during the first year of life was significantly higher among children with wheezing $(P=0.002)$ and rhinitis $(P=0.006)$. There was also a significant direct association between wheezing and mother's education level $(P=0.001)$ (Table 4).

Table 1. The prevalence rates of wheezing and asthma symptoms among school children

\begin{tabular}{|c|c|c|c|c|}
\hline \multirow{2}{*}{ Symptoms } & \multirow{2}{*}{ Girls (\%) } & \multirow{2}{*}{ Boys $(\%)$} & \multicolumn{2}{|r|}{ Total } \\
\hline & & & Number & Percent $(95 \%$ CI $)$ \\
\hline Ever wheezing & $119(31.1)$ & $106(26.1)$ & 225 & $28.1(27-36)$ \\
\hline $\begin{array}{l}\text { Wheezing since } 12 \\
\text { months }\end{array}$ & $67(17.5)$ & $45(10.8)$ & 112 & $14(11-18)$ \\
\hline $\begin{array}{l}\text { Wheezing attacks/ month } \\
\qquad \begin{array}{c}1-3 \\
4-12 \\
>12\end{array}\end{array}$ & $\begin{array}{l}37(9.7) \\
2(0.52) \\
2(0.52)\end{array}$ & $\begin{array}{l}35(8.4) \\
2(0.48) \\
2(0.48)\end{array}$ & $\begin{array}{c}72 \\
4 \\
4\end{array}$ & $\begin{array}{c}9 \\
0.5 \\
0.5\end{array}$ \\
\hline
\end{tabular}




\begin{tabular}{|c|c|c|c|c|}
\hline \multirow{2}{*}{ Symptoms } & \multirow{2}{*}{ Girls (\%) } & \multirow{2}{*}{ Boys $(\%)$} & \multicolumn{2}{|r|}{ Total } \\
\hline & & & Number & Percent $(95 \%$ CI $)$ \\
\hline $\begin{array}{c}\text { Night problem / week } \\
<1 \text { night } \\
>1 \text { night }\end{array}$ & $\begin{array}{l}43(11.2) \\
5(1.2)\end{array}$ & $\begin{array}{l}32(7.8) \\
8(1.9)\end{array}$ & $\begin{array}{l}75 \\
13\end{array}$ & $\begin{array}{l}9.6 \\
1.7\end{array}$ \\
\hline Speech problem & $8(2.1)$ & $6(1.4)$ & 14 & 1.8 \\
\hline $\begin{array}{l}\text { Dry cough since } 12 \\
\text { months }\end{array}$ & $66(17.2)$ & $62(14.9)$ & 128 & $16(15-21)$ \\
\hline $\begin{array}{l}\text { Wheezing during } \\
\text { exercise }\end{array}$ & $15(3.9)$ & $20(4.8)$ & 35 & $4.5(3.5-7)$ \\
\hline Asthma & $4(1.1)$ & $4(1)$ & 8 & $1(0.6-1.2)$ \\
\hline
\end{tabular}

Table 2. The prevalence rates of rhinitis, rhinoconjunctivitis, and physician-diagnosed allergic rhinitis among school children

\begin{tabular}{|lllll|}
\hline Symptoms & Girls $(\%)$ & Boys $(\%)$ & Total & \\
& & & Number & Percent $(95 \%$ CI) \\
\hline Rhinitis & $78(20.4)$ & $82(19.7)$ & 160 & $20(19-27)$ \\
\hline Rhinitis during 12 months & $78(20.4)$ & $62(15.2)$ & 140 & $17.9(17-24)$ \\
\hline $\begin{array}{l}\text { Rhinoconjenctivitis } \\
\text { Impact on daily activity }\end{array}$ & $39(10.4)$ & $38(9.4)$ & 77 & $9.6(8.5-12)$ \\
$\begin{array}{l}\text { Mild } \\
\text { Moderate }\end{array}$ & $48(12.5)$ & $53(12.7)$ & 101 & 12.6 \\
$\begin{array}{l}\text { Allergic Rhinitis } \\
28(7.3)\end{array}$ & $25(0.5)$ & $4(0.9)$ & 53 & 6.6 \\
\hline
\end{tabular}

Table 3. The prevalence of dermatitis symptoms, severity, and physician-diagnosed eczema among school children

\begin{tabular}{lcccc}
\multicolumn{1}{c}{ Symptoms } & Girls (\%) & Boys (\%) & Number & Percent (95\% CI) \\
\hline Itchy rash & $73(19)$ & $62(14.8)$ & 135 & $16.8(13.1-17.5)$ \\
\hline Rash during 12 months & $59(15.4)$ & $38(9.1)$ & 97 & $12.4(12-17)$ \\
Sleep disorder & $34(8.8)$ & $20(4.7)$ & 54 & 6.7 \\
< 1 nigh per week & $28(7.3)$ & $18(4.3)$ & 46 & 5.7 \\
> 1 night per week & $6(1.5)$ & $2(0.5)$ & 8 & 1 \\
Age of appearance & $28(7.3)$ & $23(5.5)$ & 51 & 6.4 \\
<2 year & $21(5.4)$ & $15(3.6)$ & 36 & 4.5 \\
2-4 year & $24(6.3)$ & $24(5.7)$ & 48 & 6 \\
\hline 5 year & $22(5.7)$ & $11(2.6)$ & 33 & $4.1(3-6)$ \\
\hline Eczema & & & & \\
\hline
\end{tabular}


Table 4. The assessment of demographic and environmental factors in children with asthma, rhinitis, and dermatitis symptoms in comparison to children without these symptoms

\begin{tabular}{|c|c|c|c|c|c|c|c|c|c|}
\hline \multirow{2}{*}{ Variable } & \multicolumn{2}{|c|}{ Asthma } & \multirow{2}{*}{ PV } & \multicolumn{2}{|c|}{ Rhinitis } & \multirow{2}{*}{ PV } & \multicolumn{2}{|c|}{ Eczema } & \multirow{2}{*}{ PV } \\
\hline & yes & no & & yes & no & & yes & no & \\
\hline Wight(Kg) & $24.8 \pm 5.1$ & $24.04 \pm 5.04$ & $0.01 *$ & $24.6 \pm 5.5$ & $24.06 \pm 5.7$ & 0.14 & $23.9 \pm 3.8$ & $24.3 \pm 5.1$ & 0.8 \\
\hline Height(cm) & $122.6 \pm 8.5$ & $120.9 \pm 13.4$ & 0.16 & $120.8 \pm 13.2$ & $121.8 \pm 11.4$ & 0.27 & $119.7 \pm 13.5$ & $121.5 \pm 12.1$ & 0.61 \\
\hline $\begin{array}{l}\text { Birth weight } \\
\text { (gr) }\end{array}$ & $2480 \pm 510$ & $2474 \pm 504$ & 0.21 & $2464 \pm 550$ & $2406 \pm 479$ & 0.14 & $2392 \pm 388$ & $2428 \pm 509$ & 0.8 \\
\hline Fast food $(\%)$ & 73.6 & 71.2 & 0.112 & 67.8 & 60.4 & 0.09 & 88.8 & 61.8 & $0.004 *$ \\
\hline$\dagger$ BMF (\%) & 87.6 & 88.6 & 0.96 & 78 & 80.2 & 0.84 & 75 & 80 & 0.95 \\
\hline $\begin{array}{l}\text { Pet exposure } \\
\text { first year }(\%)\end{array}$ & 11.2 & 5.3 & $0.008 *$ & 8.6 & 6.1 & 0.08 & 18.1 & 6.9 & $0.004 *$ \\
\hline $\begin{array}{l}\text { Recent pet } \\
\text { exposure }(\%)\end{array}$ & 11.6 & 7.6 & $0.05^{*}$ & 9.8 & 8.2 & $0.05^{*}$ & 18.1 & 9 & $0.001 *$ \\
\hline $\begin{array}{l}\text { Domestic First } \\
\text { year }(\%)\end{array}$ & 10.7 & 6.1 & $0.008 *$ & 12.8 & 5.2 & $0.004^{*}$ & 18.1 & 7.3 & $0.002 *$ \\
\hline $\operatorname{Tobacco}(\%)$ & 28.4 & 30.4 & 0.73 & 41.3 & 23.8 & $0.001 *$ & 42.8 & 25.8 & $0.008 *$ \\
\hline $\begin{array}{l}\text { Paracetamol } \\
(\%)\end{array}$ & 90.3 & 78.2 & $0.000 *$ & 87 & 65 & 0.003 & 78 & 82 & 0.81 \\
\hline Antibiotic (\%) & 50.3 & 39.5 & $0.002 *$ & 48.6 & 39.5 & $0.006^{*}$ & 50 & 43.5 & 0.35 \\
\hline $\begin{array}{c}\square \text { Heavy } \\
\operatorname{traffic}(\%)\end{array}$ & 34.1 & 41.3 & 0.06 & 43.3 & 36.4 & 0.11 & 35.7 & 38.7 & 0.4 \\
\hline $\begin{array}{l}\text { Mother collage } \\
\text { education }(\%)\end{array}$ & 70.5 & 57.1 & $0.001 *$ & 62.3 & 60.6 & 0.69 & 53.8 & 61.7 & 0.48 \\
\hline $\begin{array}{l}\text { TV watching > } 5 \\
\text { hr/day }(\%)\end{array}$ & 27.9 & 26.3 & 0.16 & 28 & 20 & 0.09 & 27.4 & 22.1 & 0.37 \\
\hline Activity > 3/wk & 42.5 & 26.5 & $0.000 *$ & 37.6 & 27.6 & $0.01 *$ & 38.6 & 29.7 & $0.012 *$ \\
\hline$>2$ siblings & 8.8 & 16.1 & 0.052 & 14.2 & 14.4 & 0.69 & 15.9 & 14.7 & 0.92 \\
\hline
\end{tabular}

$\dagger$ : Breast milk feeding; $\square:$ Almost all day long trucks pass through the street

\section{Discussion}

Our study showed that about $28 \%$ of children had wheezing, and $14 \%$ had recent wheezing; these rates are higher than those reported by Mohammadzadeh and coworkers, whose study was done in the northern part of Iran, although lower night symptoms were presented in our study (4.6\% vs. 1,7\%) (18). Another investigation in the western part of Iran reported a higher prevalence of recent wheezing, exerciseinduced, and sleep problems (19). On the other hand, the rate of physician-diagnosed asthma in our study was $1 \%$, which is much lower than similar reports and is approximately three times lower than the value presented in a systematic review study that illustrated asthma prevalence rates in several parts of Iran $(10,18$, 20). The prevalence of recent wheezing is 14 times higher than doctor-diagnosed asthma. Regarding differences in access to health care services, parents' concerns about the term of asthma, the risk of bias, and denying on the diagnoses that make by physicians, relying on wheezing symptoms may be more accordable.
The prevalence of rhinitis symptoms was $20 \%$, and that of allergic rhinitis was $8.9 \%$, which is lower than results among adolescents $(15,21,22)$, although some studies in preschool children showed a higher prevalence of rhinitis symptoms $(14,23)$. However, several studies presented lower rates of rhinitis among 6- to 7-year-old children in comparison with our results $(18,24)$. The time and period of exposure to environmental allergens, along with genetic factors in different geographic areas, could explain this variability.

We found that $135(16.8 \%)$ children had a history of itchy rashes, $12.4 \%$ had a current itchy rash, and $4.1 \%$ had confirmed eczema. These findings are in accordance with the results of several studies involving children (12, 25, 26). However, some studies, particularly in tropical and northern areas, showed a higher frequency of atopic dermatitis $(4,6,11,27,28)$. The period of exposure and higher contact with environmental allergens in these areas could be an important factor that induces higher rates of sensitization and dermatitis. 
Although there is a higher risk of allergic disorders among boys during childhood $(12,26,29,30)$, our study showed that asthma and atopic dermatitis in girls were significantly higher than in boys. This is consistent with the study of Masjedi et al., who reported a higher rate of wheezy girls than boys (20). There was also a similar distribution of allergic rhinitis among boys and girls in our study. It seems that lifestyle and habitual factors, in addition to genetic or environmental factors, must be considered as probable risk factors for female vs. male predominance.

We found a significant association between asthma and the weight of children, which is compatible with our previous study in children (31). There were significant associations between mother's education, exposure to pets and domestic animals, and antibiotic and paracetamol consumption in the first year of life and asthma. The increased risk of asthma with antibiotics and paracetamol use has been confirmed in many investigations. While some of these factors were shown to have protective effects in some studies, they were shown to be risk factors in others $(1,32-36)$. Increasing hygiene and reduction of exposure to infectious pathogens is likely an important factor for increasing $\mathrm{T}$ helper 2 (Th2) cell activation and rising allergic trend in susceptible subjects.

Allergic rhinitis was higher among children exposed to parental tobacco smoking, domestic animals, and paracetamol and antibiotics use during the first year of life. Consistent with our study, Safari and coworkers showed that smoking and pet exposure were high among children with allergic rhinitis (22). However, this association was not shown in the study of Salarnia et al. (14). Children with atopic dermatitis had high rates of fast food consumption and parental tobacco smoking. In a large logistic regression study, there were strong associations between paracetamol use and early-life antibiotics and eczema among 6- to 7-yearold children. In addition, high associations were reported with current paracetamol use, open-fire cooking, and exposure to heavy traffic and risk of atopic dermatitis (37).

It has been confirmed that atopic dermatitis is an important risk factor for asthma and allergic rhinitis, and close correlations between allergic rhinitis, asthma, and atopic dermatitis have been observed $(11,27,38)$. Therefore, the etiology and risk factors for the appearance and exacerbation of these disorders could be similar. However, the period and route of contact with various allergens in different environments might induce different symptoms of allergies.

\section{Conclusion}

We found high frequencies of asthma symptoms, allergic rhinitis, and dermatitis among primary school children. Thus, preventive measures, along with the early detection of atopy based on allergic symptoms, might be informative and reduce the burden of these disorders.

\section{Acknowledgments}

This study was derived from a thesis approved by the Research Council of Zanjan University of Medical Sciences, and its Ethic Committee Record No. is ZUMS.REC.1394.243. We would like to thank all the children, parents, and teachers for helping us in this study.

\section{Conflict of Interest}

Authors declared no conflict of interest.

\section{References}

1. Del-Rio-Navarro BE, Navarrete-Rodríguez EM, Berber A, Reyes-Noriega N, García-Marcos Álvarez L. The burden of asthma in an inner-city area: A historical review 10 years after Isaac. World Allergy Organ J. 2020;13(1):100092. [DOI:10.1016/j.waojou.2019.100092]

2. Bateman ED, Hurd SS, Barnes PJ , et al. Global strategy for asthma management and prevention: GINA executive summary. Eur Respir J. 2008;31(1):143-78.

[DOI:10.1183/09031936.00138707]

3. Mehta R. Allergy and Asthma: Allergic Rhinitis and Allergic Conjunctivitis. FP Essent. 2018;472:11-5.

4. Goh YY, Keshavarzi F, Chew YL. Prevalence of atopic dermatitis and pattern of drug therapy in malaysian children. Dermatitis. 2018;29(3):15161. [DOI:10.1097/DER.0000000000000376]

5. Roduit C, Frei R, Depner M, et al. Phenotypes of atopic dermatitis depending on the timing of onset and progression in childhood. JAMA Pediatr. 2017;171(7):655-62. [DOI:10.1001/jamapediatrics.2017.0556]

6. Spergel JM. Epidemiology of atopic dermatitis and atopic march in children. Immunol Allergy Clin North Am. 2010;30(3):269-80. [DOI:10.1016/j.iac.2010.06.003]

7. Khan DA. Allergic rhinitis and asthma: epidemiology and common pathophysiology. Allergy Asthma Proc. 2014;35(5):357-61. [DOI:10.2500/aap.2014.35.3794]

8. Ferrante G, La Grutta S. The burden of pediatric asthma. Front Pediatr. 2018;22;6:186. [DOI:10.3389/fped.2018.00186]

9. Sharifi L, Dashti R, Pourpak Z, et al. Economic burden of pediatric asthma: Ann Cost Dis Iran. Iran J Public Health. 2018;47(2):256-63. 
10. Ghaffari J, Aarabi M. The prevalence of pediatric asthma in the Islamic Republic of Iran: A systematic review and meta-analysis. J Pediatr Rev 2013;1(1):2-11.

11. Farrokhi S, Gheybi MK, Movahhed A, et al. Prevalence and risk factors of asthma and allergic diseases in primary schoolchildren living in Bushehr, Iran: phase I, III ISAAC protocol. Iran $\mathbf{J}$ Allergy Asthma Immunol. 2014;13(5):348-55.

12. Ghaffari J, Mohammadzadeh I, Khalilian A, Rafatpanah H, Mohammadjafari H, Davoudi A. Prevalence of asthma, allergic rhinitis and eczema in elementary schools in Sari (Iran). Caspian J Intern Med. 2012;3(1):372-6.

13. Zamanfar D, Gaffari J, Behzadnia S, YazdaniCharati J, Tavakoli S. The prevalence of allergic rhinitis, eczema and asthma in students of guidance schools in Mazandaran province, Iran. Open Access Maced J Med Sci. 2016;4(4):61923. [DOI:10.3889/oamjms.2016.112]

14. Salarnia S, Momen T, Jari M. Prevalence and risk factors of allergic rhinitis in primary school students of Isfahan, Iran. Adv Biomed Res. 2018;7:157 [DOI:10.4103/abr.abr_194_18]

15. Ahmadiafshar A, Parchegani MR, Moosavinasab $\mathrm{N}$, Koosha A. A study of relation between BCG scar and atopy in schoolchildren of Zanjan city. Iran J Allergy Asthma Immunol. 2005;4(4):1858.

16. Ahmadiafshar A, Ghoreishi A, Afkhami Ardakan iS, Khoshnevisasl P, Faghihzadeh S, Nickmehr P. The high prevalence of depression among adolescents with asthma in Iran. Psychosom Med. 2016;78(1):113-4. [DOI:10.1097/PSY.0000000000000286]

17. ISAAC Committee. Worldwide variations in the prevalence of atopic diseases: the international study of asthma and allergies in childhood (ISAAC). Lancet 1998;351:1225-32. [DOI:10.1016/S0140-6736(97)07302-9]

18. Mohammadzadeh I, Ghafari J, Barari Savadkoohi R. The prevalence of asthma, allergic rhinitis and eczema in North of Iran. Iran J Pediatr. 2008;18(2):117-22.

19. Nasiri Kalmarzi R, Shekari A, Tajik M, et al. The prevalence of asthma symptoms in elementary and middle school students in Kurdistan province, the West of Iran. Int $\mathrm{J}$ Pediatr. 2016;4(26):1323-30.

20. Masjedi MR, Fadaizadeh L, Najafizadeh K, Dokouhaki P. Prevalence and severity of asthma symptoms in children of Tehran- International Study of Asthma and Allergies in Childhood (ISAAC). Iran $\mathbf{J}$ Allergy Asthma Immunol 2004;3(1):25-30.
21. Barr JG, Al-Reefy H, Fox AT, Hopkins C. Allergic rhinitis in children. BMJ. 2014;349:g4153. [DOI:10.1136/bmj.g4153]

22. Safari M, Jari M. Prevalence of allergic rhinitis in 13-14 year old school children in Hamedan. Iran J Pediatr. 2008;18(S1):41-6.

23. Kim HY, Kwon EB, Baek JH, et al. Prevalence and comorbidity of allergic diseases in preschool children. Korean J Pediatr. 2013;56(8):338-42. [DOI:10.3345/kjp.2013.56.8.338]

24. Ramírez-Soto M, Bedolla-Barajas M, GonzálezMendoza T. Prevalence of asthma, allergic rhinitis and atopic dermatitis in school children of the Mexican Bajío region. Rev Alerg Mex. 2018;65(4):372-8.

[DOI:10.29262/ram.v65i4.527]

25. Aberle N, Kljaić Bukvić B, Blekić M, et al. Allergic diseases and atopy among schoolchildren in Eastern Croatia. Acta Clin Croat. 2018;57(1):82-90. [DOI:10.20471/acc.2018.57.01.09]

26. Stipić-Marković A, Pevec B, Pevec MR, Custović A. Prevalence of symptoms of asthma, allergic rhinitis, conjunctivitis and atopic eczema: ISAAC (International Study of Asthma and Allergies in Childhood) in a population of schoolchildren in Zagreb. Acta Med Croatica. 2003;57(4):281-5.

27. Hwang CY, Chen Y, Lin MW, et al. Prevalence of atopic dermatitis, allergic rhinitis and asthma in Taiwan: a national study 2000 to 2007 . Acta Derm Venereol. 2010;90(6):589-94. [DOI:10.2340/00015555-0963]

28. Ahmed A, Hakim A, Becker A. Evaluation of eczema, asthma, allergic rhinitis and allergies among the grade- 1 children of Iqaluit. Allergy Asthma Clin Immunol. 2018;14(9):10.1186/s13223-018-0232-2. [DOI:10.1186/s13223-018-0232-2]

29. Mirzaei M, Karimi M, Beheshti S, Mohammadi M. Prevalence of asthma among middle eastern children: a systematic review. Med J Islam Repub Iran. 2016;31:9 [DOI:10.18869/mjiri.31.9]

30. Lau S, Matricardi PM, Wahn U, Lee Y, Keil T. Allergy and atopy from infancy to adulthood: Messages from the German birth cohort MAS. Ann Allergy Asthma Immunol. 2019;122(1):2532. [DOI:10.1016/j.anai.2018.05.012]

31. Ahmadiafshar A, Tabbakhha S, Mousavinasab N, Khoshnevis P. Relation between asthma and body mass index in 6-15 years old children. Acta Medica Iranica. 2013;51(9):615-19.

32. Asher MI, Stewart AW, Mallol J, et al. Which population level environmental factors are 
associated with asthma, rhinoconjunctivitis and eczema? Review of the ecological analyses of ISAAC Phase One. Respir Res. 2010;11:10.1186/465-9921-11-8. [DOI:10.1186/1465-9921-11-8]

33. Hammer-Helmich L, Linneberg A, Thomsen SF, Glümer C. Association between parental socioeconomic position and prevalence of asthma, atopic eczema and hay fever in children. Scand J Public Health. 2014;42(2):120-7. [DOI:10.1177/1403494813505727]

34. Ghozikali MG, Ansarin K, Naddafi K, et al. Prevalence of asthma and associated factors among male late adolescents in Tabriz, Iran. Environ Sci Pollut Res Int. 2018;25(3):2184-93. [DOI:10.1007/s11356-017-0553-6]

35. Gergen PJ, Mitchell HE, Calatroni A, et al. Sensitization and exposure to pets: the effect on asthma morbidity in the US population. J Allergy
Clin Immunol Pract. 2018;6(1):101-7. [DOI:10.1016/j.jaip.2017.05.019]

36. Silverwood RJ, Rutter CE, Mitchell EA, et al. Are environmental risk factors for current wheeze in the international study of asthma and allergies in childhood (ISAAC) phase three due to reverse causation? Clin Exp Allergy. 2019;49(4):430-41. [DOI:10.1111/cea.13325]

37. Rutter CE, Silverwood RJ, Williams HC, et al. Are environmental factors for atopic eczema in ISAAC phase three due to reverse causation? J Invest Dermatol. 2019;139(5):1023-36. [DOI:10.1016/j.jid.2018.08.035]

38. Ferreira MA, Vonk JM, Baurecht H, et al. Shared genetic origin of asthma, hay fever and eczema elucidates allergic disease biology. Nat Genet. 2017;49(12):1752-7. [DOI:10.1038/ng.3985]

\section{How to Cite This Article:}

Ahmadiafshar A, Nourollahi S, Arminpour A, Faghihzadeh S. The Prevalence and Risk Factors of Asthma, Allergic Rhinitis, and Eczema in Primary School Children, Zanjan, Iran. J Adv Med Biomed Res. 2020 ; 28 (130) :230-236

\section{Download citation:}

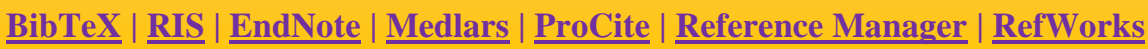

\section{Send citation to:}

Mendeley 2 Zotero : 